\title{
REFERENTIALITY IN NOUN PHRASES AND RELATIVE PRONOUNS
}

\author{
Chiaki Kumamoto
}

\begin{abstract}
This paper examines the use of who and which with human antecedents in non-restrictive relative clauses. Apart from the cases where the antecedent is a property NP, the contexts that require which are claimed to be those where the antecedent is a non-specific NP (Kuno 1970, Declerck 1991). However, the use of which is not limited to these cases. Moreover, there are cases where which is not allowed even though the antecedent is a non-specific NP. I will argue that in order to fully account for the choice between who and which, it is crucial to consider not only the referentiality and the specificity of the antecedent NP but also the semantic function that the relative pronoun plays in the clause, specifically, whether it is a referential NP, a property NP, or an NP involving a variable.
\end{abstract}

\section{Key words}

copular sentences, existential sentences, relative pronouns, referential/non-referential distinction, noun phrases involving a variable

\section{Introduction}

This paper proposes to clarify the conditions under which the relative pronoun which is used with human antecedents in non-restrictive relative clauses, using constructed data. Although the choice between who and which typically depends on whether the antecedent is human or non-human, there are cases where which occurs with antecedents denoting human beings. It has been pointed out that which is required if the antecedent NP is a predicational NP or a non-specific NP (Kuno 1970, Declerck 1991). However, the antecedent NPs in the following examples have distinct characteristics, and it is essential to examine the semantic functions they perform in the given clauses.

(1) The witness says the robber was a tall man, which this suspect is not.

(Declerck 1991: 538)

(2) I am looking for a specialist, which you do not happen to be.

(Declerck 1991: 539)

(3) There is always a girl taking care of John like his mother, which there shouldn't be.

(4) I know Tom's murderer, which I'll let you know in a minute.

(Kumamoto 1995: 23) 
Moreover, as seen in Example (2), the function the antecedent NP performs in the main clause and the function the relative pronoun performs in the relative clause are not necessarily the same, which makes the investigation more complicated. The crucial factors that determine the choice between who and which are the referentiality and the specificity of the antecedent NP and the semantic function the relative pronoun performs in the clause; furthermore, the notion of 'noun phrase involving a variable' (henceforth NPIV) is indispensable to fully explain the referential/non-referential distinction of noun phrases.

\section{Critical review of research}

\subsection{Declerck (1991)}

A review of previous explanations for the use of which in non-restrictive relative clauses with human antecedents will provide a basis for discussion. Declerck (1991) states that we use which instead of who if the relative pronoun does not refer to a specific person or group of persons but is used 'predicationally'. In his terminology, an NP is used 'predicationally' if it denotes a quality or characteristic. He classifies cases of the relative pronouns being used predicationally into two types exemplified by Examples (1) and (5), and (2) and (6).

(5) They call him a coward, which he was not.

(Declerck 1991: 539) What we all need is a loving partner, which you don't have.

(Declerck 1991: 539)

He observes that Examples (1) and (5) are cases where the relative pronoun is the subject complement in the non-restrictive relative clause, while Examples (2) and (6) are cases where the antecedent is an indefinite NP with non-specific reference.

Interestingly, he mentions not only a condition on the relative pronoun but also a condition on the antecedent NP in his explanation of the use of which with human antecedents. However, he does not clearly state which condition precedes in determining the choice between which and who. In Example (2), for instance, the relative pronoun which is used. Is it because the relative pronoun is the subject complement in the non-restrictive relative clause, or is it because the antecedent NP is an indefinite NP with the non-specific reading? It is also problematic to assert that the relative pronoun is predicationally used in (6) because the antecedent is an NP with non-specific reference. In this relative clause, which is the object of the verb have and does not serve the function of describing a property or quality. 
Declerck's explanation is inadequate because he seems to consider that the relative pronoun which whose antecedent is a non-specific NP is predicationally used in every case. It is misleading to subsume predicational NPs, which the relative pronouns in (1), (2) and (5) function as, and a distinct type of NP without specific reference, which the relative pronoun in (6) functions as, under the same category of predicationally used noun phrases. What semantic function the relative pronoun which in (6) performs is a problem we shall be concerned with later. At this point, it is important to recognize a crucial difference between predicational NPs and non-specific indefinite NPs. Predicational NPs are property denoting and therefore non-referential in nature, while non-specific indefinite NPs are referential in the sense that they refer to entities in the world. Although nonspecific indefinite NPs are type-denoting and do not establish specific referents (Ioup 1977), they serve the function of referring and should not be classified into the category of predicationally used NPs. We will consider referentiality and non-referentiality of various types of NPs in greater detail below.

\subsection{Huddleston and Pullum (2002)}

Huddleston and Pullum (2002) (henceforth H \& P) offer a different explanation for the occurrence of the relative pronoun which with antecedents denoting human beings in their Examples (7)-(9).

(7) They accused him of being a traitor, which he undoubtedly was.

(H \& P 2002: 1048)

(8) They've got a chief executive who can provide strong leadership, which we certainly haven't got at the moment.

(H \& P 2002: 1049)

(9) Remember that they have a house-keeper, which we don't have.

(H \& P 2002: 1049)

Example (7) involves relativisation of the predicative complement of be. They state "the relativized predicative in the which construction will generally be of the ascriptive type, ... the clause is concerned with the person's properties, what kind of person he was, and not his identity" (ibid.: 1048). Example (7) is contrasted with Example (10), where the issue is the identity of the person.

It turned out that he wasn't the person who I'd thought he was.

(H \& P 2002: 1048)

Examples (8) and (9), on the other hand, are cases where the complement of have or have got is relativized. They point out that also in these examples identity is 
not at issue. What these examples convey, they claim, is that we have not got the same kind of chief executive, or the same kind of thing (i.e. a house-keeper), and not that we have not got the same chief executive or the same house-keeper.

They offer a unified explanation for the use of which with human antecedents exemplified by Examples (7)-(9) in terms of "unconcern for the identity of the person". Their proposal is useful but limited. They do not, for example, make clear what they mean by the term 'identity'. In (11), both which and who are allowed with a human antecedent.

(11) Smith's murderer, which/who happened to be/turned out to be Jones, was arrested last night.

At first glance, it seems that the non-restrictive clause is concerned with the identity of the person referred to by the antecedent Smith's murderer, irrespective of whether which or who is selected. To explicate the choice between which and who in the relative clause of (11), however, we need to distinguish between specificational sentences and identity sentences. We shall be concerned with major types of copular sentences in the next section. Here I would like to point out that when Huddleston and Pullum state "Who would be impossible here (=in Example (7)), but is used in the integrated relative clause of [ii] $(=(10))$, with be used in its specifying sense: the issue is the identity of the person (I thought he was person $\mathrm{x}$, but he turned out not to be)" (Huddleston \& Pullum 2002: 1048, my emphasis), they do not clearly distinguish between specificational sentences and identity sentences. Secondly, they do not explain what kind of NPs the antecedents in Examples (8) and (9) are, although they mention that the antecedent NP in (7) functions as a predicative complement, suggesting that the NP is a predicational NP. It is tempting to characterize the antecedent NPs in (8) and (9) to be non-specific NPs, but the main clauses in these examples do not necessarily imply that the speaker does not have any specific chief executive or any specific housekeeper in mind. Incidentally, I would like to add that the definition of specificity in terms of the notion of speaker identifiability is debatable (cf. von Heusinger 2002, Kagan 2006). If these antecedents cannot properly be characterized as non-specific NPs, what type of NPs are they? We are sure that the antecedent NP and the relative pronoun in these examples are not 'co-referential'. If the relative pronoun were to refer to the same individual referred to by the antecedent, not which but who would be selected. It must also be determined if these 'kind-denoting' NPs are referential or not in the first place, a point to be taken up below with reference to the semantic relation detected between Examples (3) and (12). 
(12) John always has a girl taking care of him like his mother, which he shouldn't have.

In short, neither Declerck (1991) nor Huddleston and Pullum (2002) satisfactorily explain the use of which with human antecedents in non-restrictive relative clauses. They only treat cases where the antecedent NP is an indefinite NP, and completely ignore cases where the antecedent NP is a definite NP, exemplified by (4) and (11). Moreover, they do not carefully observe the semantic functions performed by the antecedent NP and the relative pronoun in respective clauses. The shortcomings of these treatments warrant a consideration of semantic types of main clause and relative clause and an examination of the semantic functions the antecedent NP and the relative pronoun perform, with special attention to the distinction between referential and non-referential functions of the NPs.

\section{Clause types and the choice between which and who}

\subsection{Semantic structures of copular sentences and existential sentences}

The types of sentences to be discussed in this section are given below, with copular sentences in the form of $A$ is $B / B$ is $A$, exemplified by (13)-(15), treated first.

$\frac{\text { John }}{\text { referential NP }}$

is a doctor. predicational NP

a. Smith's murderer is $\quad$ Jones. (inverted specificational sentence) NPIV ([x is Smith's murderer]) referential NP

b. Jones is $\quad$ Smith's murderer. (specificational sentence) referential NP NPIV ([x is Smith's murderer])

a. The Evening Star is the Morning Star. (identity sentence) referential NP referential NP

b. The Morning Star is the Evening Star. (inverted identity sentence) referential NP referential NP

(16) There are two books on the desk.

(locative existential sentence)

referential NP

(17) There are two books required for the course.

(absolute existential sentence) NPIV ([ $\mathrm{x}$ is the book required for the course])

(Nishiyama 2013: 258) 
Example (13) is an example of a predicational sentence. A predicational sentence $A$ is $B$ is a type of sentence that ascribes the property denoted by $B$ to the referent of $A$. $A$ is $B$ in (14a) and $B$ is $A$ in (14b) are examples of an inverted specificational sentence and a specificational sentence, respectively. The word order is reversed, but the meaning conveyed remains the same. These sentences assign the value indicated by $B$ to the variable indicated by $A$. The nature of an NP that represents a variable is best explained in terms of the notion of NPIV, namely, an NP involving a variable, proposed by Nishiyama $(2003,2013)$. It is a noun phrase that denotes a propositional function that involves a variable [...x...]. It does not refer to an entity in the world, and therefore, non-referential. An identity sentence and its inversion are given in (15a) and (15b). In an identity sentence $A$ is $B$ and an inverted identity sentence $B$ is $A, A$ and $B$ are both referential NPs. Identity sentences are used to assert the identity between the referent of $A$ and the referent of $B$, and often called 'equatives'. Some linguists confuse (inverted) specificational sentences with (inverted) identity sentences, but their semantic structures are totally different. An NP that appears in the position of $\mathrm{A}$ is referential in (inverted) identity sentences but non-referential in (inverted) specificational sentences.

This distinction between referential NPs and NPIVs in copular sentences simplifies an understanding of how they function in the existential sentences in (16) and (17). To use Nishiyama's $(2003,2013)$ terminology, (16) is an example of a locative existential sentence and (17) is an example of an absolute existential sentence. A locative existential sentence There is $A$ in $L$ describes the existence of an entity or entities A in the locative space L. The NP in the position of A is a referential NP and a locative expression is indispensable in this type of sentence. An absolute existential sentence, on the other hand, describes the existence of a value or values for $\mathrm{x}$ that satisfies the propositional function $[\ldots \mathrm{x} . .$.$] . In this case,$ the NP in the position of A is an NPIV, which is non-referential, and a locative expression is irrelevant. What (17) says is that there are two values that satisfy the propositional function [ $\mathrm{x}$ is the book required for the course] and the sentence can be paraphrased as You need to read two books to take the course.

We have distinguished between referential NPs and non-referential NPs, and, among the latter, between predicational NPs and NPIVs. The next step is to examine what determines the choice between who and which, with special reference to the functions of the antecedent NP and the relative pronoun perform in respective clauses. There are cases where the semantic function of the antecedent NP is the same as that of the relative pronoun and cases where their functions differ. Examples in which a predicational clause, a specificational clause or an existential clause appears in the main clause and/or in the relative clause will provide the basis for the discussion. 


\subsection{Predicational clauses}

As noted in the introduction, the relative pronoun which is selected when the antecedent is a predicational NP. Example (18) illustrates this point.

$$
\text { He is a hypocrite, which/*who I don't want to become. }
$$

(Kuno 1970: 348)

In (18), both the antecedent NP and the relative pronoun have the function of predicational NP. If the relative pronoun is to function as a referential NP while the antecedent NP is a predicational NP, the sentence is unacceptable, as in (19).

$$
\text { *John is a good teacher, which/who I can trust. }
$$

However, this does not mean that the function of the antecedent NP and that of the relative pronoun should be always the same. In the acceptable sentences (20) and (21), the antecedent NPs are both referential NPs (a non-specific indefinite $\mathrm{NP}$ and a generic NP, respectively), and the relative pronouns are predicational NPs.

$(20=(2))$ I am looking for a specialist, which you do not happen to be.

(Declerck 1991: 539)

(21) A career girl, which my fiancée doesn't happen to be, attracts me most.

(Kuno 1970: 349)

Since a non-specific NP does not refer to a particular individual but rather indicates a type of person, it is understandable that which is used when the antecedent NP is a non-specific NP. A generic NP is a kind-referring NP and does not make specific reference either. The contrast between the non-specific reading and the specific reading of the NP an obedient girl is reflected in the choice between which and who in (22).

(22) John is looking for an obedient girl, which/who we haven't seen recently.

(Kumamoto 1995: 22)

Example (22) demonstrates that which can be used even though the relative pronoun functions not as a predicational NP but as a referential NP, if the referential NP is read as non-specific. In contrast, which is not allowed in (23) with the non-specific reading, where the relative pronoun is the subject of a predicational clause. 
(23)

We are looking for a good teacher, *which/who could be a non-native speaker of English.

In (23), the NP a good teacher is interpreted as non-specific, and yet only the relative pronoun who is allowed. The reason for this is that the modal verb could contained in the relative clause creates an imaginary world where the existence of a certain referent of the NP a good teacher is assumed. In contrast, only the specific reading of an obedient girl is possible in (24), because the relative clause does not contain a modal verb.

John is looking for an obedient girl, *which/who is a student at Harvard.

The choice of which is dependent, therefore, on the non-referential or nonspecific reading of the human antecedent NP. It is interesting to note here that Kuno (1970) gives an example where the relative pronoun which occurs with a human antecedent NP with the specific reading.

The defendant says that he robbed a brunette, which the witness is not.

(Kuno 1970: 349)

In Example (25), Kuno (1970: 349) points out the defendant robbed a specific brunette. Donnellan's (1966: 285) notion of 'attributively used NP' can be used to explain such cases. In this sentence, the NP a brunette is used attributively; it is used not to pick out a particular individual but to assert something about someone who fits the description. Since non-specific NPs are always used attributively, it would be better to say that which occurs with a human antecedent when the antecedent is a referential NP interpreted attributively, rather than to say that it does so when the antecedent is a referential NP read as non-specific.

To summarize, the relative pronoun which is used in non-restrictive relative clauses with antecedents denoting human beings in the following cases: (i) the antecedent is a predicational NP and the relative pronoun is also a predicational $\mathrm{NP}$, (ii) the antecedent is an indefinite referential NP with the attributive reading and the relative pronoun is a predicational NP, (iii) the antecedent is a referential NP with the non-specific reading and the relative pronoun is also a referential NP with the non-specific reading, on the condition that the relative pronoun is not the subject of the predicational clause. 


\subsection{Specificational clauses}

Cases where either or both of the clauses are specificational require clarification. In (26), both the main clause and the relative clause are specificational.

(26) People might consider Robinson, and not Jones, to be Smith's murderer, which ${ }^{*}$ who I would rather consider to be Jones.

(Kumamoto 1995: 23)

The antecedent NP Smith's murderer functions as an NPIV and which also functions as an NPIV. In each clause, one of the values Robinson and Jones is chosen and assigned to the variable [x is Smith's murderer]. Example (27) is an example in which only the relative clause is specificational.

(27) Everyone wants to find out Smith's murderer, which/*who the police suspect to be Jones.

The relative clause of (27) specifies the value for the variable [ $\mathrm{x}$ is Smith's murderer]. The relative pronoun functions as an NPIV in the specificational clause, but what kind of NP is the antecedent? A comparison of (27) with (28) and (29) will help answer this question. The underlined NPs in (28a) and (29a) are known as concealed questions. These NPs have the meaning of embedded $w h$ questions. Nishiyama $(2003,2013)$ points out that these NPs are in fact NPIVs.

a. James figured out the plane's arrival time.

b. James figured out what the plane's arrival time would be.

(29) a. Fred tried to guess the amount of the stolen money.

b. Fred tried to guess how much money had been stolen.

(Baker 1968: 81)

Similarly in (27), the NP Smith's murderer is the object of the question-embedding phrasal verb find out. We can understand that the NP Smith's murderer functions as an NPIV in the main clause. The use of which is then easily explained, as an NPIV is non-referential and does not refer to an individual. The ambiguity of the verb know, however, affects the choice between which and who, as shown in (30) and (31).

(30) I know Smiths murderer, which/*who I'll let you know in a minute.

(31) I know Smith's murderer very well, *which/who may not know me, though. 
In (30), the verb know means that the subject has the answer to the question Who/ Which one is Smith's murderer? The NP Smith's murderer functions as an NPIV in the main clause, and the relative pronoun which also functions as an NPIV in the relative clause. The relative clause tells that the speaker will let the hearer know the answer to the question Who/Which one is Smith's murderer? However, in (31) the verb know means that the subject is familiar with a particular person who is described as Smith's murderer. The speaker has a certain referent in mind, and the NP Smith's murderer functions as a referential NP. This time, the relative pronoun who is chosen, because the relative pronoun functions as a referential NP in the relative clause. The relative clause conveys that the particular person described as Smith's murderer may not be familiar with the speaker.

In the examples cited above, both the antecedent NP and the relative NP are NPIVs. When the semantic functions of the antecedent NP and that of the relative pronoun are different, an unacceptable sentence may result, as in (32).

*We suspect Jones, and not Robinson, to be Smith's murderer, which/who the police are going to arrest immediately.

Here, the main clause contains a specificational clause, and the NP Smith's murderer is an NPIV. The relative pronoun, on the other hand, is the object of the verb arrest and should be interpreted as referential. The mismatch between the semantic function of the antecedent NP and that of the relative pronoun makes (32) unacceptable. It should be noticed, however, that such a mismatch is allowed in (33).

(33) The police finally found out Smith's murderer, *which/who they are going to arrest immediately.

This may be because the existence of the specific referent of the NP Smith's murderer can be pragmatically inferred after the value for the variable has been assigned. The same pragmatic inference may explain the acceptability of which in (34).

Smith's murderer, which/who turned out to be Jones, was arrested last night.

In (34), the NP Smith's murderer functions as a referential NP in the main clause. If who is chosen, the relative pronoun functions as a referential NP, and the relative clause is an identity statement; it describes that the referent of Smith's 
murderer is identical with the referent of Jones. In this case, there is no mismatch between the function of the antecedent and that of the relative pronoun. If which is chosen, however, there is a mismatch between them. The relative pronoun functions as an NPIV, while the antecedent is a referential NP. The explanation we can propose for this is, again, that after the specification has taken place, we can infer the existence of a referent that fits the description of the antecedent NP. Accordingly, only the attributive reading of the NP Smith's murderer is possible. The reason which is permissible here is that the referential function of the NP Smith's murderer has not been made explicit before the specification takes place. Complex cases like these invite further investigation.

Now, we can give two more cases where the relative pronoun which is used in non-restrictive relative clauses with human antecedents: (iv) the antecedent is an NPIV and the relative pronoun is also an NPIV, (v) the antecedent is a referential NP interpreted attributively and the relative pronoun is an NPIV, on the condition that the semantic function of the antecedent NP is not made explicit before the specification takes place.

\subsection{Existential clauses}

Finally, there are cases in which either or both clauses are existential clauses. As pointed out in Section 3.1, the distinction between locative existential sentences and absolute existential sentences is crucial and apparent in the two different readings of (35), as in (36) and (37).

(35) There is something John wouldn't eat.

(36) There is something John wouldn't eat in the fridge.

(37) There is something John wouldn't eat. It's eels.

(locative existential sentence)

(absolute existential sentence)

The NP something John wouldn't eat is a referential NP in (36) while it is an NPIV in (37). The choice between who and which in existential clauses can be explained in terms of referentiality and non-referentiality of the antecedent NPs.

(38) There is a girl taking care of John in his room now, *which there shouldn't be/who shouldn't be there.

(Kumamoto 1995: 27)

(39) There is always a girl taking care of John, which there shouldn't be/*who shouldn't be there.

(Kumamoto 1995: 27) 
Example (38) describes the physical existence of a girl in the room. Example (39), on the other hand, states the existence of a value that satisfies the propositional function [x is the girl who takes care of John]. The speaker of (39) means that no one should take care of John, not that a certain girl shouldn't occupy some physical space. The antecedent NP and the relative pronoun are both referential NPs in (38), and they are both NPIVs in (39). Examples (40) and (41) are cases where an existential clause is followed by a copular clause.

(40) There is a guy smart enough to solve this problem in the next room, ${ }^{*}$ which/who is my brother/also a good athlete.

(Kumamoto 1995: 26)

(41) There surely is a guy smart enough to solve this problem, which/who I suppose, is my brother/no one but John.

(Kumamoto 1995: 26)

The main clause of (40) is a locative existential clause and the antecedent NP is referential. The relative pronoun is the subject of the predicational or identity clause and has to be referential, so the relative pronoun who is selected. The main clause of (41), in contrast, is an absolute existential clause and the antecedent NP is an NPIV. The relative pronoun which is the subject of the specificational clause and functions as an NPIV. The use of who in this sentence is explained in terms of the pragmatic inference that has been mentioned before. First, the main clause asserts the existence of a value for the variable and then, the relative clause reveals the identity of the referent of the assumed value NP.

In short, all the cases where the relative pronoun occurs with human antecedents we have treated in this section are cases where the antecedent NP and the relative pronoun are both NPIVs. It is worth pointing out here that the semantic functions of the antecedent NP and the relative pronoun in Examples (42) and (43) can also be explained employing the notion of NPIV.

$(42=(8))$ They've got a chief executive who can provide strong leadership, which we certainly haven't got at the moment.

(H \& P 2002: 1049)

$(43=(9))$ Remember that they have a house-keeper, which we don't have.

(H \& P 2002: 1049)

The close connection between absolute existential sentences and possessive constructions is mentioned in Nishiyama (2003, 2013). By following Nishiyama and interpreting these sentences as having an absolute existential sentence 
incorporated inside their semantic structure, one can eliminate the notion of 'kind-denoting' NPs. Nishiyama (2013: 292) proposes a semantic structure of the Japanese equivalent of (44), which is roughly illustrated in (45).

(44) John has a sister.

$$
\text { binds }
$$

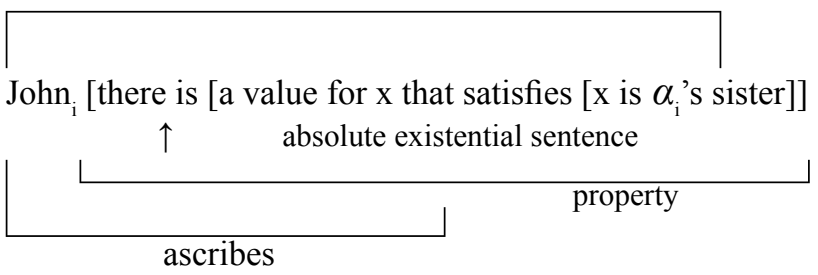

He considers a possessive construction to be a kind of predicational sentence which ascribes the property of there being a value that satisfies the propositonal function to the referent of the subject NP. The semantic relation between possessive constructions and absolute existential sentences is easily detected. It is interesting to note the difference in choice of relative pronoun in the following examples.

(46) I have an aunt, which you don't.

(47) I have an aunt, whom you haven't met.

(48) I have an aunt with me here, whom I'm going to introduce to you.

In (46) and (47), the NP an aunt is an NPIV. The main clause in each sentence asserts that the speaker has a property such that the value that satisfies the propositional function [ $\mathrm{x}$ is $\alpha$ 's aunt] is not empty. The reason which is used in (46) is that the relative pronoun functions as an NPIV in the relative clause. In (47), on the other hand, the relative pronoun functions as a referential NP, and thus, whom is selected. There is a mismatch between the semantic function of the antecedent and that of the relative pronoun in (47). After the existence of a value for the variable is asserted, however, we can easily infer the existence of the specific referent of the NP the speaker's aunt. This makes (47) acceptable. In contrast with these two examples, (48) contains a main clause that asserts the physical existence of an aunt. The NP an aunt is referential in this case. As there is no binding relation between the subject NP and $\alpha$ in ' $\alpha$ 's aunt' assumed here, the NP an aunt does not necessarily refer to the speaker's aunt. To make this point clear, we may imagine a television host introducing the winner of the "Aunt of the Year" using the sentence in (49) (Dr. Jember, personal communication). 
I've got a truly amazing aunt with me here, whom I'm going to introduce to you.

If Examples (42) and (43) are interpreted in the same way as (46), a chief executive in (42) and a house-keeper in (43) are considered to be NPIVs. The non-referentiality of these NPs and the semantic function the relative pronoun performs in the relative clause explain the use of which in (42) and (43). This is an interesting issue but one to be left for future investigation.

\section{Conclusion}

I have argued that the choice between the relative pronouns who and which in non-restrictive relative clauses with human antecedents depends on the semantic functions the antecedent NP and the relative pronoun perform. In cases where there is a mismatch between the function of the antecedent NP and that of the relative pronoun, the function of the relative pronoun takes precedence in determining the choice. The distinction between referential NPs and non-referential NPs is of paramount importance, but this dichotomy alone cannot account for all usages. More extensive studies of the characteristics of attributively used NPs, NPs with non-specific reading, predicational NPs and NPIVs are needed in order to fully explain the choice of relative pronouns.

Note

This research was supported by a Grant-in-Aid for Scientific Research (KAKEN) (C) \#24520433. I am grateful to Dr. Gregory K. Jember for acting as a native-speaker informant and for suggesting stylistic improvements.

\section{References}

Baker, C. L. (1968) Indirect Questions in English. Ph.D. dissertation. University of Illinois.

Declerck, R. (1991) A Comprehensive Descriptive Grammar of English. Tokyo: Kaitakusha.

Donnellan, K. S. (1966) 'Reference and definite descriptions.' The Philosophical Review 75, 281-304.

Huddleston, R. and Pullum, G. K. (2002) The Cambridge Grammar of the English Language. Cambridge: Cambridge University Press.

Ioup, G. (1977) 'Specificity and the interpretation of quantifiers.' Linguistics and Philosophy 1/2, 233-245.

Kagan, O. (2006) 'Specificity as speaker identifiability.' Proceedings of Ninth Symposium on Logic and language (LoLa 9), Besenyotelek, Hugary, August 24-29, 2006, 82-89. http://www.nytud.hu/lola9/proceedings/kagan.pdf\#search='Kagan+Olga+specificity'

Kumamoto, C. (1995) 'Meishiku no shijisei to kankeidaimeishi.' (Relative pronouns and referentiality of noun phrases) The University of Saga Studies in English 23, 19-32.

Kuno, S. (1970) 'Some properties of non-referential noun phrases.' In: Jakobson, R. and 
Kawamoto, S. (eds) Studies in General and Oriental Linguistics. Tokyo: TEC. 348373.

Nishiyama, Y. (2003) Nihongo Meishiku no Imiron to Goyooron. (Semantics and Pragmatics of Noun Phrases in Japanese) Tokyo: Hituzi Syobo.

Nishiyama, Y. (ed.) (2013) Meishiku no Sekai-Sono Imi to Shinpi no Sekai ni Semaru. (On Noun Phrases: The Mystery of Meaning and Interpretation) Tokyo: Hituzi Syobo. von Heusinger, K. (2002) 'Specificity and definiteness in sentence and discourse structure.' Journal of Semantics 19, 245-274.

Chiaki Kumamoto is Professor of English Linguistics at Saga University, Saga, Japan. Her main research interests are the semantics and pragmatics of copular and existential sentences in English and Japanese, with special emphasis on referentiality and non-referentiality of noun phrases. By comparing the semantic functions of noun phrases in Japanese copular and existential sentences with their English equivalents, she has clarified and resolved several misunderstandings about their semantic structures.

Address: Prof. Chiaki Kumamoto, MA, Division of European and American Cultural Studies, Faculty of Culture and Education, Saga University, 1 Honjo, Saga, 840-8502, Japan. [e-mail: chiaki@cc.saga-u.ac.jp] 